Volume 2, Issue 2, April-June 2017, Pages: 189, DOI: http://dx.doi.org/10.19082/ah189

\title{
RECOMMENDATIONS FOR REGISTRATION AND SURVEILLANCE SYSTEM OF OCCUPATIONAL TOXICITIES AND DISEASES
}

\author{
Seyedeh Negar Assadi
}

Associate Professor, Management and Social Determinants of Health Research Center, Department of Occupational Health Engineering, School of Health, Mashhad University of Medical Sciences, Mashhad, Iran

\section{Correspondence:}

Seyedeh Negar Assadi, Management and Social Determinants of Health Research Center, Department of Occupational Health Engineering, School of Health, Mashhad University of Medical Sciences, Mashhad, Iran. Email: assadin@mums.ac.ir

\section{TYPE OF ARTICLE: CONFERENCE ABSTRACT}

\begin{abstract}
Introduction: Occupational toxicities and diseases must be registered and have a surveillance system so that they could be treated and followed up better and sooner. The objective is the recommendations for a registration and surveillance system of occupational toxicities and diseases.

Methods: This is a review study using occupational toxicology and medicine references and evidence based on recent related journals, websites and related facts including; Centers for Disease Control and Prevention, National Institute for Occupational Safety and Health, Occupational Safety and Health Administrations, World Health Organization, International Agency for Research on Cancer, and the International Labor Organization.

Results: All occupational toxicities and diseases must be registered and surveilled. Designing and implicating the related program could be helpful. There are some recommendations. In the registry of occupational toxicities and diseases it is recommended that these criteria be observed; neuropathy from occupational toxicities and from neurological diseases must be distinguished, the disorders such as nephrological toxicities from occupational toxins should be diagnosed and differentiated from kidney diseases too. Occupational toxicities and diseases require treatment and follow-ups. Surveillance programs must be done with examinations and biologic monitoring. All issues are required to be recorded on both electronic and printed type.

Conclusion: Registry and surveillance for occupational toxicities and diseases must be done and followed up until complete improvement.

KEYWORDS: Registry, Surveillance, Occupation, Toxicity, Disease
\end{abstract}

\footnotetext{
Abstracts of First National Congress of Medical Informatics, Mashhad, Iran, February 2017

(C) 2017 The Authors. This is an open access article under the terms of the Creative Commons Attribution-NonCommercialNoDerivs License, which permits use and distribution in any medium, provided the original work is properly cited, the use is non-commercial and no modifications or adaptations are made.
} 